\title{
Happy to help? A systematic review and meta-analysis of the effects of performing acts of kindness on the well-being of the actor ${ }^{\text {th }}$
}

\author{
Oliver Scott Curry ${ }^{\mathrm{a}, *}$, Lee A. Rowland ${ }^{\mathrm{b}, \mathrm{e}}$, Caspar J. Van Lissa ${ }^{\mathrm{c}, \mathrm{f}}$, Sally Zlotowitz $^{\mathrm{d}}$, John McAlaney ${ }^{\mathrm{b}}$, \\ Harvey Whitehouse ${ }^{\text {a }}$
}

a Institute of Cognitive and Evolutionary Anthropology, University of Oxford, United Kingdom

${ }^{\mathrm{b}}$ Department of Psychology, Bournemouth University, United Kingdom

${ }^{\mathrm{c}}$ Methodology \& Statistics, Social and Behavioural Sciences, Utrecht University, Netherlands

${ }^{\mathrm{d}}$ Department of Clinical Educational and Health Psychology, University College London, United Kingdom

e School of Anthropology and Museum Ethnography, University of Oxford, United Kingdom

${ }^{\mathrm{f}}$ Erasmus School of Social and Behavioural Sciences, Erasmus University Rotterdam, Netherlands

\section{A R T I C L E I N F O}

Handling editor: Elizabeth Page-Gould

Keywords:

Kindness

Well-being

Altruism

Happiness

Positive psychology

\begin{abstract}
A B S T R A C T
Do acts of kindness improve the well-being of the actor? Recent advances in the behavioural sciences have provided a number of explanations of human social, cooperative and altruistic behaviour. These theories predict that people will be 'happy to help' family, friends, community members, spouses, and even strangers under some conditions. Here we conduct a systematic review and meta-analysis of the experimental evidence that kindness interventions (for example, performing 'random acts of kindness') boost subjective well-being. Our initial search of the literature identified 489 articles; of which 24 (27 studies) met the inclusion criteria (total $N=4045$ ). These 27 studies, some of which included multiple control conditions and dependent measures, yielded 52 effect sizes. Multi-level modeling revealed that the overall effect of kindness on the well-being of the actor is small-tomedium $(\delta=0.28)$. The effect was not moderated by sex, age, type of participant, intervention, control condition or outcome measure. There was no indication of publication bias. We discuss the limitations of the current literature, and recommend that future research test more specific theories of kindness: taking kindness-specific individual differences into account; distinguishing between the effects of kindness to specific categories of people; and considering a wider range of proximal and distal outcomes. Such research will advance our understanding of the causes and consequences of kindness, and help practitioners to maximise the effectiveness of kindness interventions to improve well-being.
\end{abstract}

\section{Introduction}

Do acts of kindness improve the well-being of the actor? Over the past few decades, advances in the behavioural sciences have developed numerous theories of human social, cooperative and altruistic behaviour. These theories - kin altruism, mutualism, reciprocal altruism, and competitive altruism - make it possible to explain a variety of different types of kindness (for example, love, sympathy, gratitude and heroism). And they predict that people will be 'happy to help' family, friends, community members, spouses, and even strangers under some conditions.

More recently, there has been growing interest in using kindness as an intervention to boost subjective well-being. The idea that, for example, 'random acts of kindness' can boost the well-being not only of the recipient, but also the actor, and could thereby provide a simple, effective, inexpensive and widely-available means of addressing social problems ranging from social isolation to more serious mental and physical health conditions, has been taken up and promoted by a large number of research groups, charities and government organisations (Aked, Marks, Cordon, \& Thompson, 2008; Aked \& Thompson, 2011; see S1; Huppert, 2009).

Here we outline existing theories of altruism and their relation to kindness, and consider the predictions these theories make about wellbeing. We then conduct a systematic review and meta-analysis of

\footnotetext{
is The work on this article was supported by kindness.org (R46536/CN001). We also thank the many researchers who generously responded to our requests for unpublished papers and

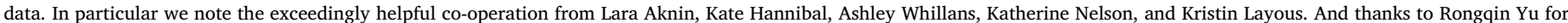

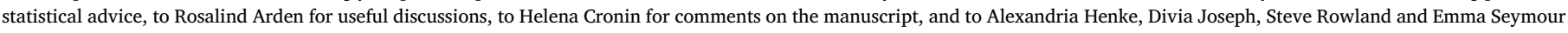
for research assistance.

* Corresponding author at: Institute of Cognitive and Evolutionary Anthropology, University of Oxford, 64 Banbury Road, Oxford, OX2 6PN, United Kingdom.

E-mail address: oliver.curry@anthro.ox.ac.uk (O.S. Curry).
} 
previous experimental studies of the effects of kind acts on the wellbeing of the actor. And we end with a discussion of the limitations of the existing literature, and make recommendations for future research.

\section{The causes of kindness}

Kindness refers to actions intended to benefit others. Why and under what circumstances are people kind to others? Why do people behave in prosocial, cooperative and altruistic ways? Recent interdisciplinary research has provided a wealth of answers to these questions (Curry, 2016).

Humans evolved from a long line of social primates, who have been living in social groups for over 50 million years (Shultz, Opie, \& Atkinson, 2011). Group living affords numerous opportunities for various different types of mutually beneficial cooperative interaction (Lehmann \& Keller, 2006; Nunn \& Lewis, 2001; Sachs, Mueller, Wilcox, \& Bull, 2004). Natural selection has favoured a range of evolved psychological mechanisms for taking advantages of these opportunities, and realising the benefits of cooperation. These mechanisms - kin altruism, mutualism, reciprocal altruism, and competitive altruism make it possible to identify and explain several different types of kindness.

\subsection{Kin Altruism: people will be kind to their families}

Natural selection favours kindness to genetic relatives, to family members (Hamilton, 1964). Examples of such 'kin altruism' are widespread in nature (Gardner \& West, 2014), most obviously in cases of parental care (Royle, Smiseth, \& Kölliker, 2012). Humans too possess adaptations for detecting and delivering benefits to kin (Lieberman, Tooby, \& Cosmides, 2007; Mateo, 2015), especially to offspring (Geary \& Flinn, 2001). Kin altruism can explain kindness in the form of love, care, sympathy and compassion. And the theory predicts that these tendencies will be elicited by others who exhibit cues of genetic relatedness, especially vulnerable children (Platek, Burch, Panyavin, Wasserman, \& Gallup Jr, 2002).

\subsection{Mutualism: people will be kind to members of their communities}

Natural selection favours the tendency to coordinate, collaborate and be kind to others with whom the actor shares a common interest team mates, group members, coalition partners. Such 'mutualisms' - for the purpose of collective defence, or collaborative hunting - are widespread in nature (Bissonnette et al., 2015; Boinski \& Garber, 2000; Boos, Kolbe, Kappeler, \& Ellwart, 2011; Harcourt \& Waal, 1992), and are an ancient and recurrent feature of human social life (Alvard, 2001; Wrangham, 1999). This process has led, in humans, to a psychology that forms and maintains groups (clubs, gangs, clans, sects, nations, and so on), and acts to promote their interests (sometimes at the expense of rival groups) (Balliet, Wu, \& De Dreu, 2014). Mutualism can explain kindness in the form of loyalty, solidarity, camaraderie, civic-mindedness, community spirit, and commitment to a cause 'greater than oneself'. The theory predicts that these tendencies will be elicited by other members of the groups with which one identifies (including strangers) (Whitehouse \& Lanman, 2014).

\subsection{Reciprocal Altruism: people will be kind to those they might meet again}

Natural selection favours kindness to those who might return the favour at a later date (Axelrod, 1984; Trivers, 1971). ${ }^{1}$ Surprisingly, few if any examples of such 'reciprocal altruism' have been found in nonhuman species (Amici et al., 2014; Clutton-Brock, 2009). But in

\footnotetext{
${ }^{1}$ For further discussion of various subtypes of reciprocity, such as indirect and network reciprocity, see (Roberts, 2008; Tanimoto, 2015)
}

humans, reciprocal altruism is implemented by psychological mechanisms that: detect those in need of help, initiate cooperation, signal recognition of favours received, keep track of who has returned the favour and who has not, make amends for favours not returned, and accept repentant cheats back into the fold (Cosmides \& Tooby, 2005; McCullough, Kurzban, \& Tabak, 2013; Trivers, 1971). Thus, reciprocal altruism can explain kindness in the form of sympathy (for those in need), trust (initiating cooperation), returning favours, gratitude (for favours yet to be returned), forgiveness and friendship. Reciprocal altruism predicts that these tendencies will most likely be elicited in repeated interactions where individuals expect to meet again, where one's cooperative (or uncooperative) behaviour can be observed by others, and towards others who have helped them in the past, or will be able to help them in the future (Kraft-Todd, Yoeli, Bhanot, \& Rand, 2015). This can includes kindness to strangers: a kind act may be a way of making a new friend; after all, 'a stranger is just a friend you haven't met yet' (Delton, Krasnow, Cosmides, \& Tooby, 2011; Krasnow, Delton, Tooby, \& Cosmides, 2013).

\subsection{Competitive Altruism: people will be kind to others when it enhances their status}

Natural selection also favours kindness that impresses peers and attracts mates (Gintis, Smith, \& Bowles, 2001; Maynard Smith \& Price, 1973). Many animals resolve status competition by engaging in costly displays of prowess (Hardy \& Briffa, 2013; Riechert, 1998). In humans, and perhaps some other species (Zahavi \& Zahavi, 1997), these displays includes altruistic acts that benefit the audience (Hardy \& Van Vugt, 2006; Hawkes, 1991; Hawkes, O'Connell, \& Blurton Jones, 2001; Mazur, 2005; Miller, 2000; Smith \& Bleige Bird, 2000). This 'competitive altruism' can explain kindness in the form of generosity, bravery, heroism, chivalry, magnanimity and public service. The theory predicts that these tendencies will be elicited in the presence of rivals, or potential mates, where acting altruistically may enhance one's status (Raihani \& Smith, 2015). This includes acts of kindness to strangers: helping a stranger may improve your status whether the recipient is in a position to return the favour or not (Barclay, 2011; Raihani \& Bshary, 2015).

Thus, multiple theories - kin altruism, mutualism, reciprocal altruism, competitive altruism - explain multiple types of kindness. And the human capacity for culture-the ability to invent and share new ways of living (Boyd, Richerson, \& Henrich, 2011; Pinker, 2010)—has allowed us to build and elaborate upon this benevolent biological foundation, with rules, norms and other social institutions that further inculcate and amplify cooperation and altruism (Hammerstein, 2003). These theories predict that people will be motivated to be kind to family, friends, colleagues, spouses, and even strangers under some conditions. ${ }^{2}$ And the possession of such motivational systems leads us to expect that helping others might make people happy.

\section{The consequences of kindness}

Subjective well-being - including happiness, life-satisfaction and positive affect - refers to a range positively valenced psychological states (Dolan \& Metcalfe, 2012; OECD, 2013). Why would performing kind acts improve well-being? Why would helping make you happy? Broadly speaking, happiness can be seen as an internal reward system for acting in ways that promote survival and reproduction (Buss, 2000). Happiness is: "a psychological reward, an internal signaling device that tells us that an adaptive problem has been, or is in the process of being,

\footnotetext{
${ }^{2}$ Note that the argument here is that biology and culture have equipped us to help automatically, intuitively, innocently - there is no suggestion that people are necessarily aware of the causes of their benevolent behaviour, or are acting from any ulterior motive. "The heart has its reasons of which reason knows nothing" (Pascal, 1669).
} 
solved successfully" (Hill, DelPriore, \& Major, 2013). From this perspective, it is no problem to explain why 'eating' or 'having sex' makes people happy; these behaviours meet important adaptive goals. And, for the reasons outlined above, it is equally straightforward to explain why performing acts of kindness might make people happy: it is because caring for family, maintaining coalitions, trading favours and increasing status are also important adaptive goals (Schulkin, 2011). Indeed, we might even expect helping others to produce more happiness than helping yourself: it is precisely because helping others can sometimes give a better return on investment than helping yourself that evolution has favoured kindness in the first place.

Thus, the evolutionary behavioural science approach to altruism predicts that people will be happy to help family, friends, community members, spouses, and even strangers under some conditions. This prediction has received some support from the existing literature. A large body of research has established an association between kindness and well-being (Anik, Aknin, Norton, \& Dunn, 2009; Konrath \& Brown, 2013). However, much of this research has been correlational showing, for example, that people who spend more money on others are happier (Aknin, Barrington-Leigh, et al., 2013), or people who volunteer to help others are healthier (Jenkinson et al., 2013). ${ }^{3}$ While such correlational evidence is consistent with the prediction that people will be happy to help others, it is not sufficient to establish a causal relationship between kindness and well-being. After all, it's possible that helping makes you happy; but it could also be that happiness makes you helpful, or it could be that some third variable - health, income, or personality - makes you both happy and helpful. The distinction between correlation and cause is not a mere philosophical nicety; it is a genuine difference with important practical implications. In the absence of a clear causal connection, kindness interventions may not work. They may waste time and money, or displace other more effective interventions. Worse, they may be counter-productive. If happiness causes helping (rather than the other way around), then forcing unhappy people to help may make them less happy still.

In order to establish whether performing acts of kindness can cause happiness, it is necessary to focus on the experimental literature. And so we undertook a systematic review and meta-analysis of research that met the following inclusion criteria: (a) experiments that randomly allocated participants to (b) interventions involving kind behaviour and controls and (c) subsequently measured and compared participant well-being.

\section{Methods}

In order to identify suitable experimental studies of the effects of altruism on the altruist's well-being, we conducted searches of the scientific databases Web of Science and PsychInfo for academic articles. The most recent search was conducted on 16th November 2017. The process is summarised in the flow diagram in Fig. 1. Searching topic, abstracts and keywords, we used the search string: (kindness OR altruis* OR prosocial OR co-operat* OR cooperat*) AND (wellbeing OR well-being OR happiness OR life satisfaction OR positive affect OR negative affect OR PANAS) AND (experiment* OR control OR condition OR random* OR empirical OR trial) NOT (mindfulness OR meditation OR loving-kindness). This search identified 712 articles. To this we added 36 articles identified by other means (following references in books and journal articles, Google scholar searches, viewing academic researchers' web-pages, reviewers' suggestions, and contacting authors

\footnotetext{
${ }^{3}$ Even then the effects are modest. This meta-analysis of the relationship between volunteering and health in the elderly found that volunteers were $22 \%$ less likely that non-volunteers to die during the follow-up period of the studies (Jenkinson et al., 2013). However, the import of this finding depends on the base-rate. By way of illustration, if on average 10 out of $1000(1 \%)$ non-volunteers die during the follow-up period, then a $22 \%$ percent decrease means that 7.8 out of $1000(0.78 \%)$ volunteers would die during the same period. Moreover, as this review goes on to say: "These findings were not confirmed by experimental studies."
}

to request unpublished data). After removing duplicates, we were left with 489 articles.

This initial set of 489 articles was screened. Two researchers (LAR and OSC) read the titles and abstracts. Subsequently 432 articles were excluded for not meeting the inclusion criteria. These articles were either: (a) not experimental (for example, were qualitative or correlational studies, or review papers); (b) did not involve kind behaviour (for example, they involved hypothetical or recalled kindness); (c) did not measure participant well-being (for example, they measured subsequent kindness, or the happiness of the recipient); or were otherwise off topic (for example, kindness in animal husbandry, climate change and planetary wellbeing). Cases in which the researchers disagreed were given greater scrutiny and discussed, and where no consensus was reached, the articles were included in the next stage of the analysis.

The remaining 57 articles were then read in full, and assessed for appropriateness for the meta-analysis (see S2 for the full list). This process excluded a further 33 records (and several studies from included articles) for reasons summarised in Table S1. ${ }^{4}$ At the end of this process we were left with 24 articles, containing a total of relevant 27 studies that had experimentally tested the hypothesis that kindness causes well-being.

For each of these studies we coded the following characteristics:

- mean age of sample

- sex of participants

- location of study

- type of participant (for example, whether participants were 'typically developed individuals', as opposed to having been diagnosed with some psychopathology)

- type of intervention (for example, 'random act of kindness', prosocial purchase, charitable donation)

- type of recipient (for example, whether family, friend, stranger)

- type of control condition(s) (for example, no treatment, self-kindness, other activity)

- dependent measure(s) (for example, happiness, life-satisfaction)

- size of the intervention group(s)

- size of the control group(s)

- effect size(s) (Cohen's $d$ )

Effect sizes were either taken directly from the paper, or computed from reported inferential or descriptive statistics (Lenhard \& Lenhard, 2016). For the handful of studies that reported outcomes at multiple time-points, we coded the effect closest in time to the intervention.

\section{Results}

\subsection{Study characteristics}

The characteristics of the 27 studies are presented in Table 1 . These 27 studies included a total of 4045 participants (mean proportion male $=35 \%$, mean age $=25.04, \mathrm{SD}=11.05){ }^{5}$

The majority of participants came from Canada, USA and Europe, although there were also studies conducted in South Africa, Korea and Vanuatu. Most participants were university students, although there were also two studies with children, one study of Vanuatu villagers, and one with elderly participants. Most were 'typically developed individuals', although two studies involved participants who scored

\footnotetext{
${ }^{4}$ The most highly cited paper in the kindness literature (with 597 citations at the time of the last search) purports to provide evidence that kind acts boosts the well-being of the actor (Lyubomirsky, Sheldon, \& Schkade, 2005). However, the article does not report the size of the sample, the dependent measure, or any inferential statistics (for example, effect size or significance). Email correspondence with the author revealed that the data are no longer available.

5 These averages are approximate $(\sim)$, because the age and sex ratio of the samples were not available for some studies.
} 


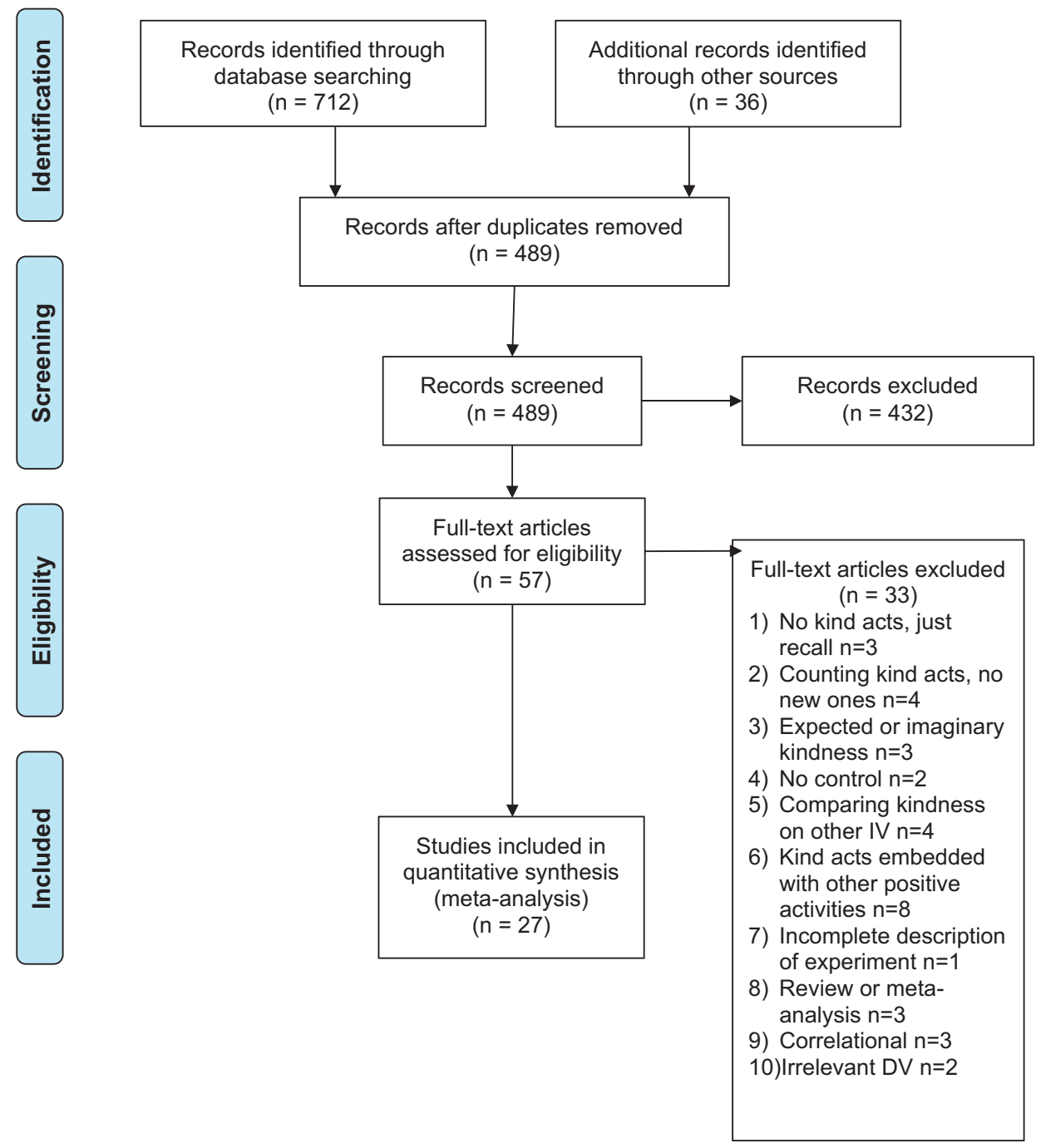

Fig. 1. Flow diagram of the search and selection procedure of studies.

highly on measures of social anxiety.

The two most common interventions were 'acts of kindness' and 'prosocial purchasing'. Typical instructions for the 'acts of kindness' intervention were as follows:

"During the coming week, please perform at least five acts of kindness per day and report on them in the evening, including the responses of others that you received. Examples of acts of kindness are: holding a door for someone at university, greeting strangers in the hallway, helping other students in preparing for an exam, etcetera. It does not matter whether you address your acts of kindness to people you know or not".

(Ouweneel, Le Blanc, \& Schaufeli, 2014)

Prosocial purchasing interventions involved giving participants a sum of money, and instructing them to spend it on someone else. Most 'acts of kindness' involved a cost; but, the 'prosocial spending' studies that involved a windfall payment to the participant did not.

The recipients of kindness included colleagues and charities, but were for the most part left unspecified, and could be 'anyone' - familiar or unfamiliar, family, friend, community member of stranger.

Control conditions also varied. Some studies compared acting kindly with doing nothing (thus possibly confounding the effects of kindness with the effects of performing any novel fun activity), whereas others compared acting kindly with some other non-social activity, or with helping oneself.
Most studies used a self-report measure of subjective well-being, happiness, life-satisfaction, or positive and negative affect. These included the Subjective Happiness Scale (SHS; Lyubomirsky \& Lepper, 1999), the Steen Happiness Index (SHI; Seligman, Steen, Park, \& Peterson, 2005), the Satisfaction With Life Scale (SWLS; Diener, Emmons, Larsen, \& Griffin, 1985), the Positive Affect and Negative Affect Scale (PANAS; Watson, Clark, \& Tellegen, 1988) and Psychological Flourishing (Lamers, Westerhof, Bohlmeijer, ten Klooster, \& Keyes, 2011). Three studies used more objective measures: two used other-rated smiling, and one used 'other rated happiness'.

Some studies had multiple control conditions, and/or multiple outcome measures, and hence provided more than one effect size; there were 52 in total.

\subsection{Descriptive statistics}

The effect size estimates ranged from -0.46 to $1.25(M=0.25$, $S D=0.32$ ). Sample sizes ranged from 26 to 474 participants ( $M=158.57, S D=132.05)$. Several studies reported multiple effect sizes (1-6, with most reporting one or two effect sizes).

\subsection{Meta-analysis}

Meta-analysis was conducted in R (R Core Team, 2017) and the Rpackages metafor (Viechtbauer, 2010), and metaforest (Van Lissa, 


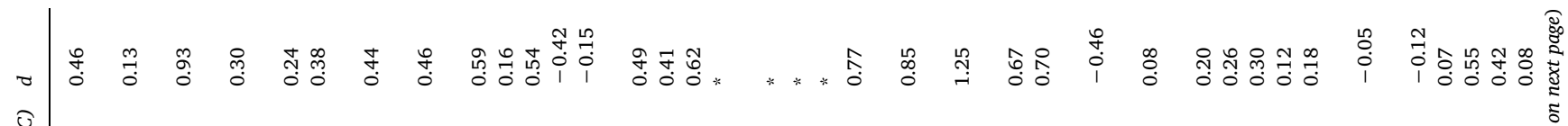
仓్ర

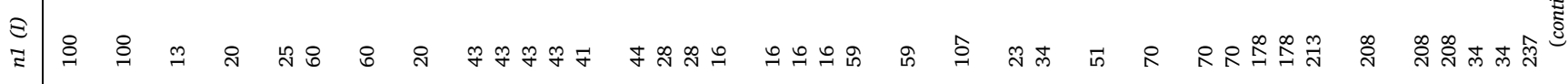
色

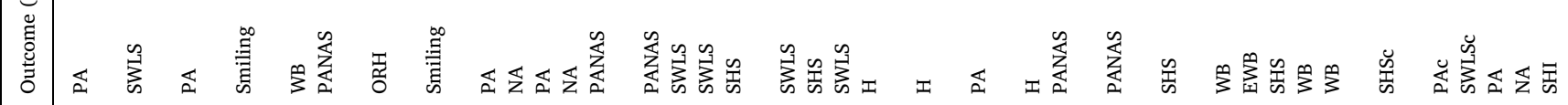

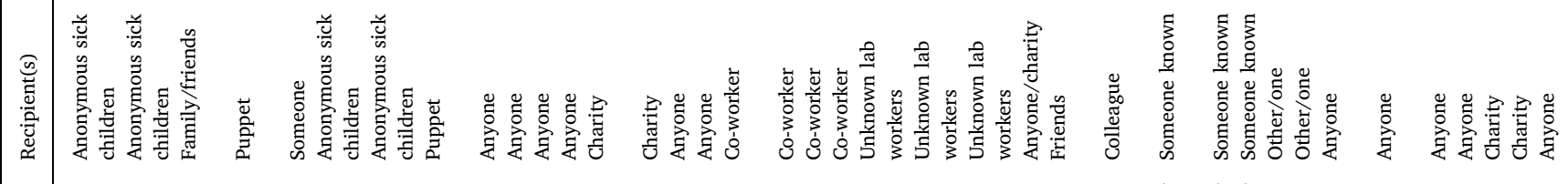

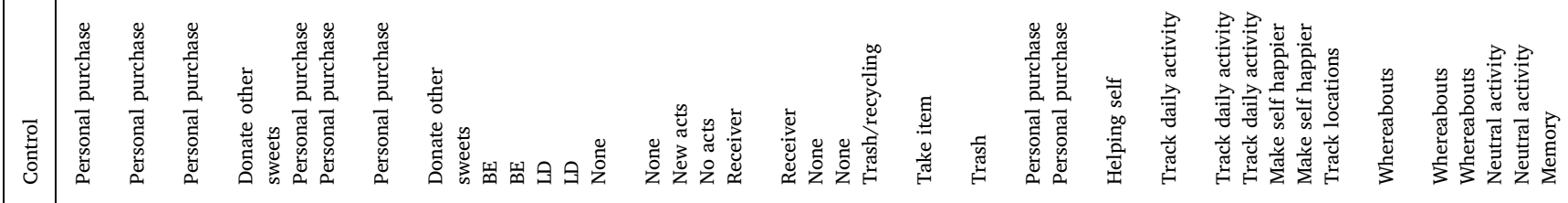

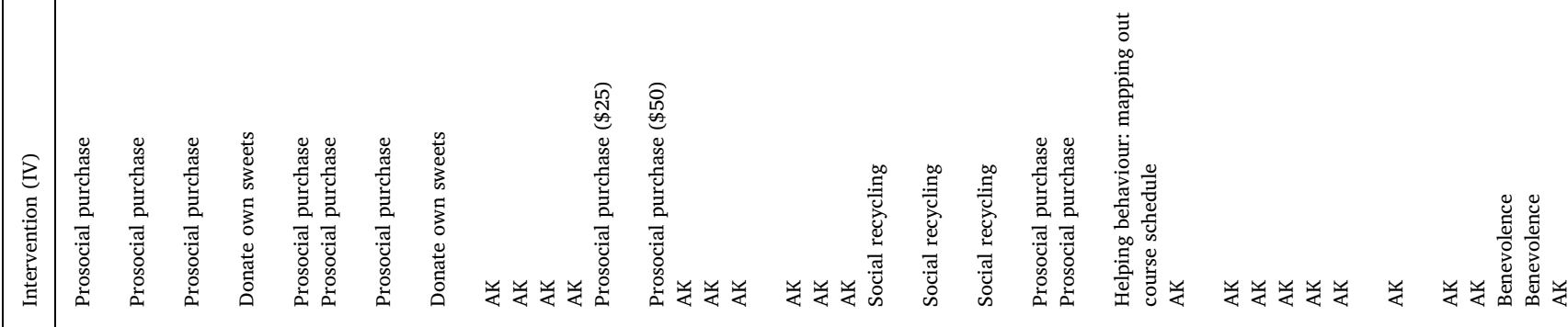

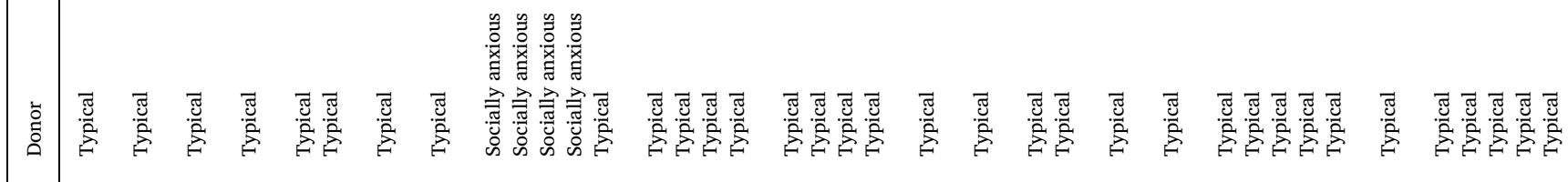

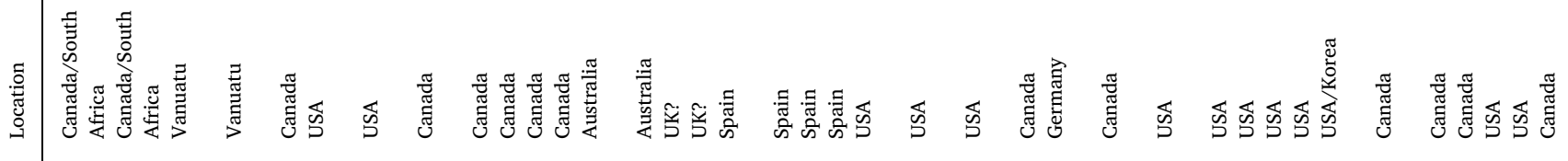

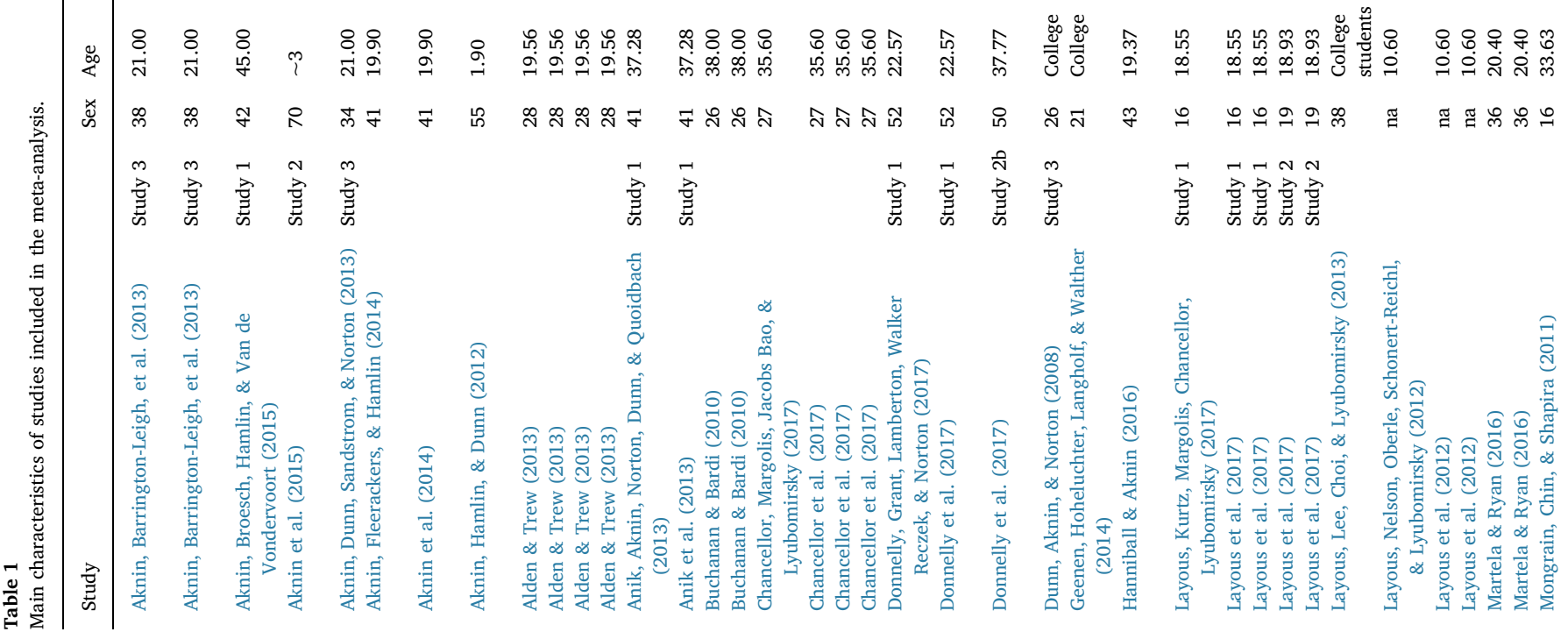




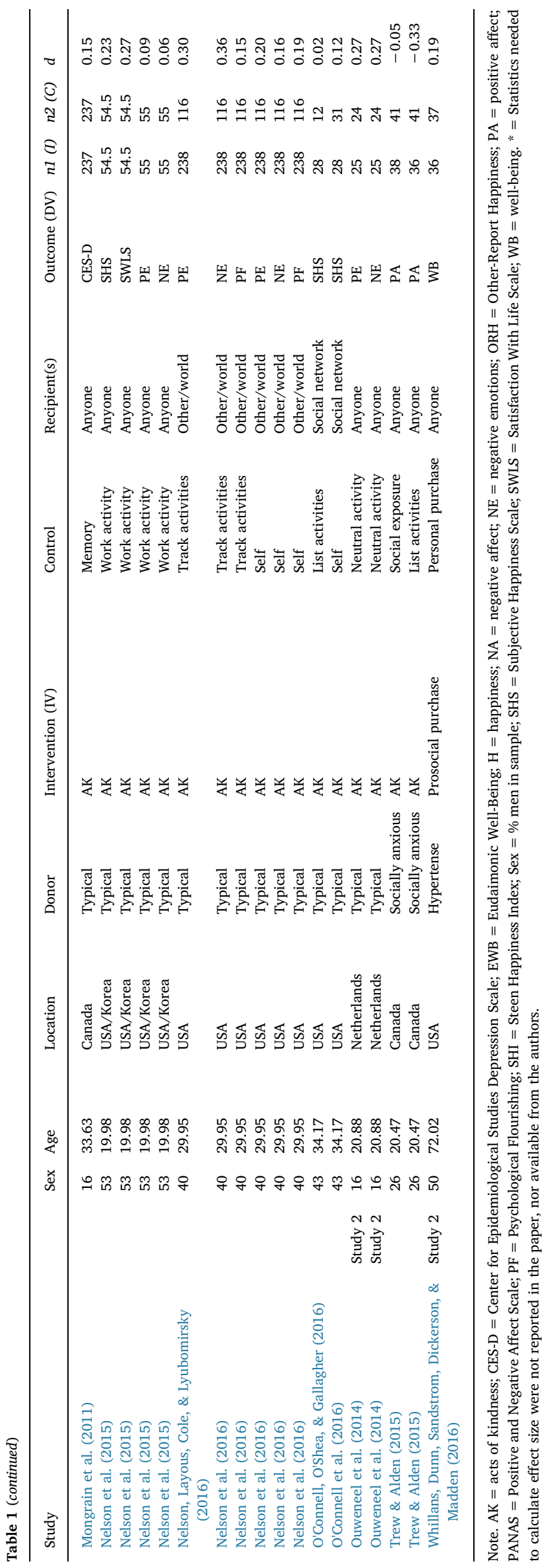

2017), following the recommendations summarised in (Field \& Gillett, 2010). We used three-level meta-analysis to account for dependent effect sizes within studies (Van den Noortgate, López-López, MarínMartínez, \& Sánchez-Meca, 2015). Let $y_{j k}$ denote the $j$ observed effect sizes $y$, originating from $k$ studies. The multi-level model is then given by the following equations:

$\left.\begin{array}{ccc}y_{j k}=\beta_{j k}+\epsilon_{j k} & \text { where }_{j k} & \sim N\left(0, \sigma_{\epsilon j k}^{2}\right) \\ \beta_{j k}=\theta_{k}+w_{j k} & \text { wherew }_{j k} & \sim N\left(0, \sigma_{w}^{2}\right) \\ \theta_{k}=\delta+b_{k} & \text { where }_{k} & \sim N\left(0, \sigma_{b}^{2}\right)\end{array}\right\}$

The first equation indicates that observed effect sizes are equal to the underlying population effect size, plus sampling error $\epsilon_{j k}$. The second equation indicates that population effect sizes within studies are a function of a study-specific true effect size, plus within-study residuals $w_{j k}$. The third equation indicates that the distribution of study-specific true effect sizes are distributed around an overall mean effect, with between-study residuals $b_{k}$. Results revealed that the overall effect size estimate was $\delta=0.28,95 \%$ CI $[0.16,0.41], Z=4.36, p<.001$ (see Fig. 2). This is a small-to-medium effect, approximately equivalent to an increase of 0.6 on a standard 0-10 happiness scale (Helliwell, Layard, \& Sachs, 2016). The within-studies variance component $\sigma_{w}{ }^{2}$ was negligible, $0.00,95 \%$ CI $[<0.01,0.02]$. The between-studies variance $\sigma_{b}^{2}$, on the other hand, differed significantly from zero, $0.08,95 \%$ CI $[0.04$, 0.18]. The fact that the between-studies component was larger than the within-studies component indicates that the variation in effect sizes was primarily accounted for by differences between studies, whereas differences between effect sizes within the same studies were negligible. Likelihood ratio tests also indicated that constraining the within-studies variance to zero would not worsen model fit, whereas constraining either the between-studies variance or both variance components to zero did lead to significant deteriorations in model fit (see Table 2). This again indicates that there was substantial heterogeneity between average effect sizes across studies, but not between effect sizes published within the same studies.

File drawer analysis (Rosenthal, 1979) revealed that 1919 unpublished, filed, or unretrieved studies averaging null results would be required to bring the average unweighted effect size to nonsignificance. Visual inspection of the Funnel plot (Fig. 3) did not clearly indicate asymmetry, which could be a sign of publication bias. Begg's test of funnel asymmetry (based on random-effects meta-analysis) similarly did not indicate significant bias, $Z=1.07, p=0.28$.

\subsection{Moderation}

We coded several potential theoretical and methodological moderators: proportion of male participants, average age of the sample, type of participant (typical, socially anxious), type of intervention (acts of kindness, prosocial spending, other), type of control condition (nothing, neutral activity, self-help, other), and outcome measure (happiness, life satisfaction, positive or negative affect or emotion, other).

The small sample size limits our ability to include these moderators in mixed-effects meta-analysis without risking overfitting (modeling random noise in the data, rather than true moderating effects). We therefore used metaforest (Van Lissa, 2017) to screen for relevant moderators. This technique uses the machine learning algorithm "random forests" to prevent overfitting, and to assess the importance of several potential moderators. An added benefit is that metaforest can capture non-linear relationships between moderators and effect size, and higher-order interactions. To this end, many (in this case, 10,000) bootstrap samples are drawn from the original data, and a models is estimated on each bootstrap sample. Then, each model's performance is evaluated on cases not part of its bootstrap sample, yielding an estimate of explained variance in new data, $R_{o o b}{ }^{2}$. We conducted random-effects weighted metaforest, with clustered bootstrapping to account for the multilevel structure of the data $\left(n_{\text {tree }}=10000\right.$, 
Aknin, Barrington-Leigh, et al. (2013)

Aknin, Barrington-Leigh, et al. (2013)

Aknin, Broesch, et al. (2015)

Aknin, Broesch, et al. (2015)

Aknin, Dunn, et al. (2013)

Aknin, Fleerackers, et al. (2014)

Aknin, Fleerackers, et al. (2014)

Aknin, Hamlin, et al. (2012)

Alden, \& Trew (2013)

Alden, \& Trew (2013)

Alden, \& Trew (2013)

Alden, \& Trew (2013)

Anik, Aknin, et al. (2013)

Anik, Aknin, et al. (2013)

Buchanan, \& Bardi (2010)

Buchanan, \& Bardi (2010)

Chancellor, Margolis, et al. (2017)

Chancellor, Margolis, et al. (2017)

Chancellor, Margolis, et al. (2017)

Chancellor, Margolis, et al. (2017)

Donnelly, Grant, et al. (2017)

Donnelly, Grant, et al. (2017)

Donnelly, Grant, et al. (2017)

Dunn, Aknin, et al. (2008)

Geenen, Hoheluchter, et al. (2014)

Hanniball \& Aknin (2016, unpublished)

Layous, Kurtz, J, et al. (under review)

Layous, Kurtz, J, et al. (under review)

Layous, Kurtz, J, et al. (under review)

Layous, Kurtz, J, et al. (under review)

Layous, Kurtz, J, et al. (under review)

Layous, Lee, et al. (2013)

Layous, Nelson, et al. (2012)

Layous, Nelson, et al. (2012)

Layous, Nelson, et al. (2012)

Martela, \& Ryan (2016)

Martela, \& Ryan (2016)

Mongrain, Chin, et al. (2011)

Mongrain, Chin, et al. (2011)

Nelson, Della Porta, et al. (2015)

Nelson, Della Porta, et al. (2015)

Nelson, Della Porta, et al. (2015)

Nelson, Della Porta, et al. (2015)

Nelson, Layous, et al. (2016)

Nelson, Layous, et al. (2016)

Nelson, Layous, et al. (2016)

Nelson, Layous, et al. (2016)

Nelson, Layous, et al. (2016)

Nelson, Layous, et al. (2016)

O'Connell, O'Shea, et al. (2016)

O'Connell, O'Shea, et al. (2016)

Ouweneel, Le Blanc, et al. (2014)

Ouweneel, Le Blanc, et al. (2014)

Trew, \& Alden (2015)

Trew, \& Alden (2015)

Whillans, Dunn, et al. (2016)
SWLS

PA

Smiling

WB

PANAS

ORH

Smiling

PA

NA

PA

NA

PANAS

PANAS

SWLS

SWLS

SHS

SWLS

SHS

SWLS

$\mathrm{H}$

$\mathrm{H}$

PA

$\mathrm{H}$

PANAS

PANAS

SHS

WB

EWB

SHS

WB

WB

$\mathrm{SHSc}$

PAC

SWLSc

PA

NA

$\mathrm{SHI}$

CES-D

SHS

SWLS

PE

NE

PE

NE

PF

$P E$

NE

PF

SHS

SHS

PE

NE

PA

PA

WB
$0.46[0.18,0.74]$

$0.13[-0.15,0.41]$

$0.93[0.12,1.74]$

$0.30[-0.32,0.92]$

$0.24[-0.32,0.80]$

$0.38[0.02,0.74]$

$0.44[0.08,0.80]$

$0.46[-0.17,1.09]$

$0.59[0.15,1.03]$

$0.16[-0.27,0.59]$

$0.54[0.11,0.97]$

$-0.42[-0.85,0.01]$

$-0.15[-0.57,0.27]$

$0.49[0.07,0.91]$

$0.41[-0.12,0.94]$

$0.62[0.08,1.16]$

$0.00[-0.59,0.59]$

$0.00[-0.59,0.59]$

$0.00[-0.60,0.60]$

$0.00[-0.60,0.60]$

$0.77[0.39,1.15]$

$0.85[0.47,1.23]$

$1.25[0.96,1.54]$

$0.67[0.08,1.26]$

$0.70[0.21,1.19]$

$-0.46[-0.84,-0.08]$

$0.08[-0.25,0.41]$

$0.20[-0.13,0.53]$

$0.26[-0.07,0.59]$

$0.30[0.04,0.56]$

$0.12[-0.14,0.38]$

$0.18[-0.05,0.41]$

$-0.05[-0.24,0.14]$

$-0.12[-0.31,0.07]$

$0.07[-0.12,0.26]$

0.55 [ $0.09,1.01]$

$0.42[-0.04,0.88]$

$0.08[-0.10,0.26]$

$0.15[-0.03,0.33]$

$0.23[-0.15,0.61]$

$0.27[-0.11,0.65]$

$0.09[-0.28,0.46]$

$0.06[-0.31,0.43]$

$0.30[0.08,0.52]$

$0.36[0.14,0.58]$

$0.15[-0.07,0.37]$

$0.20[-0.02,0.42]$

$0.16[-0.06,0.38]$

$0.19[-0.03,0.41]$

$0.02\left[\begin{array}{ll}-0.66, & 0.70]\end{array}\right.$

$0.12[-0.39,0.63]$

$0.27[-0.29,0.83]$

$0.27[-0.29,0.83]$

$-0.05[-0.49,0.39]$

$-0.33[-0.78,0.12]$

$0.19[-0.27,0.65]$

Overall estimate:

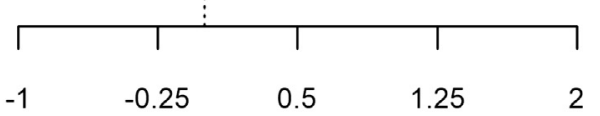

Effect size (Cohen's d)

Fig. 2. Forest plot for the effect of kindness acts on actor's well-being. 
Table 2

Model fit indices.

\begin{tabular}{lllllll}
\hline & df & AIC & BIC & II & LRT & p \\
\hline Three-level model & 3 & 22.14 & 28.16 & -8.07 & & \\
Within-studies variance constrained & 2 & 20.14 & 24.15 & -8.07 & 0 & 1 \\
Between-studies variance constrained & 2 & 33 & 36.76 & -14.37 & 12.61 & 0 \\
Both variance components constrained & 1 & 78 & 80.25 & -38.12 & 60.1 & 0 \\
\hline
\end{tabular}

Note. Significance of variance components is assessed by constraining them to zero, and examining the significance of a log-likelihood (ll) ratio test (LRT) comparing the constrained model to the full three-level model.

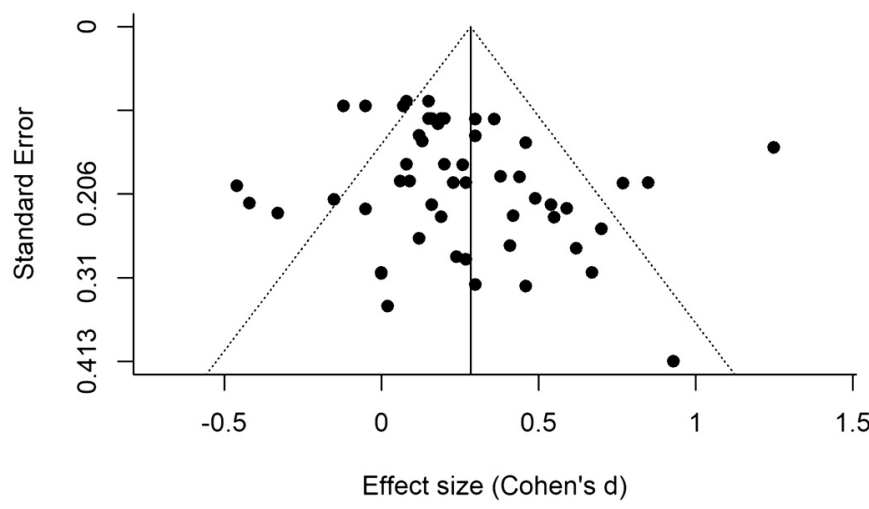

Fig. 3. Funnel plot for the effect of acts of kindness on actor's well-being.

$m_{\text {try }}=2$ ). We replicated the analysis 100 times to ensure the reliability of findings. The median estimated explained variance in out-of-bootstrap cases was negative $\left(R_{o o b}^{2}=-0.11\right)$, with a large standard deviation across replications $(S D=0.19)$. When $R_{o o b}{ }^{2}$ is negative, this means that the average effect size is a better predictor of out-of-bootstrap cases than the modelimplied predictions. In other words, the model did not capture generalizable relationships between the moderators and effect size, and we did not find evidence for associations between the moderators and effect size.

\section{Discussion}

The results of this systematic review and meta-analysis of the experimental kindness literature suggests that performing acts of kindness improves the well-being of the actor $(\delta=0.28)$. The effect of kindness is small-to-medium - comparable to other positive psychology interventions (such as 'mindfulness', 'positive thinking' and 'counting your blessings'; $\mathrm{d}=0.34$, Bolier et al., 2013; $\mathrm{d}=0.31$, Sin \& Lyubomirsky, 2009; $d=0.44$, Weiss, Westerhof, \& Bohlmeijer, 2016). ${ }^{6}$ The effect was not moderated by sex, age, type of participant, intervention, control condition or outcome measure. And there was no evidence of publication bias. Together, these results suggest that policy-makers and practitioners are correct to see kindness interventions as effective ways of improving wellbeing. And they support the general claim that, as social animals, humans possess a range of psychological mechanisms that motivate them to help others, and that they derive satisfaction from doing so.

However, in interpreting these results, a number of limitations should be kept in mind.

First, most of the reviewed studies were under-powered. The average sample size per condition was $N=79$; this gives power of only $1-\beta=0.42$ to detect a typical effect size of $d=0.28$. In order to detect such an effect with power $1-\beta=0.80$, future researchers should use a sample size of at least 202 per group (Faul, Erdfelder, Lang, \& Buchner, 2007).

Second, most of the reviewed studies used non-clinical samples of students, from Western, Educated, Industrial, Rich, Democratic

\footnotetext{
${ }^{6}$ Although see Coyne (2014a, 2014b) for critical commentary on (Sin \& Lyubomirsky, 2009) and (Bolier et al., 2013).
}

societies (W.E.I.R.D.; Henrich, Heine, \& Norenzayan, 2010). Thus it remains unclear whether the current findings would generalise to clinical samples of participants diagnosed with specific mental health problems, in non-WEIRD societies. Future research should employ more representative community samples (perhaps focussing on social disorders; Qualter et al., 2015), in a wider variety of cultures.

Third, earlier we defined kindness as 'actions intended to benefit others'. The studies reviewed here varied whether actions benefitting others were performed, they did not vary whether the benefits were intended or not - in other words, they did not manipulate the motive behind the action. Previous research has found an association between motive and outcome; one longitudinal study found that volunteers motivated by a desire to help others lived longer than non-volunteers, but that volunteers motivated by a desire to help themselves did not (Konrath, Fuhrel-Forbis, Lou, \& Brown, 2012). If this relationship is causal, then policy-makers should be aware that encouraging people to help others because of the benefits to themselves may be counter-productive - it may, somewhat paradoxically, mitigate or eliminate the effect. Further experimental research will be needed to investigate the role of intention on the benefits of helping others.

Fourth, although the finding is consistent with the general evolutionary account of altruism outlined above, existing research has not tested the more fine-grained predictions that arise from the more specific theories of helping (kin altruism, mutualism, reciprocal altruism and competitive altruism). For example, there has been little systematic investigation of whether different people benefit more from performing acts of kindness under different conditions. And studies have not systematically varied the type of recipient, for example family, colleague, friend, stranger. In fact, in most cases the recipient was left unspecified - that is, they could be 'anyone'. And so we do not know whether: people who have lost touch with their families derive more pleasure from acts of kin altruism; or whether people are happier giving to children as opposed to adults. We do not know whether, as mutualism predicts, people are be happier giving to in-group as opposed to outgroups; or whether, as reciprocal altruism predicts, people are happier giving to unlucky, as opposed to lazy, recipients (Petersen, 2012). Nor do we know whether ambitious people (with more resources to spare) seeking status are happier engaging in acts of competitive altruism, whether single people who are courting are happier helping help potential mates, or whether there are any sex differences in the satisfaction derived from different kinds of helping (Balliet, Li, Macfarlan, \& Van Vugt, 2011). Thus future work should seek to fill these gaps in our understanding. There is already a large literature on whether people behave more or less altruistically to specific types of people; it would be fairly straightforward to add measures of subjective well-being to replications and extensions of these designs.

Fifth and finally, existing research has tended to look at the immediate effects of kindness well-being. Hence it is not clear what the longer-term effects of the intervention, on well-being or more distal measures, may be. After all, previous research suggests that such effects are likely to be short-lived - 'happiness' provides an immediate reward for behaviour that has long-term benefits, and research on the 'hedonic treadmill' suggests that people might have a 'set point' that they return to whatever happens to them, good or bad (Ryan \& Deci, 2001). If the function of altruistic behaviour is to help families, make new friends, improve communities, increase status, or find a mate, then it would be instructive for future experiments to measure these hypothesised longterm benefits. Do people allocated to the kindness condition report better relations with their families? More identification with their communities? More friends? More recognition and honours? More pride in one's achievements (Sznycer et al., 2017)? More sexual partners (Arnocky, Piché, Albert, Ouellette, \& Barclay, 2016)? More committed relationships (Kogan et al., 2010)? More resilient marriages? If so, then future research might be able to finally connect the two types of happiness - short-term hedonic pleasure, and long-term eudaemonic components of the good life - that have hitherto remained apart. 


\section{Conclusion}

Helping others makes you happy, but the effect is relatively modest. Further empirical work testing the implications of more specific theories of social, cooperative and altruistic behaviour is needed to determine whether the effect might be larger for some types of helpers, when helping some types of recipients. This research will advance our understanding of the causes and consequences of kindness, and help practitioners to maximise the effectiveness of kindness interventions.

\section{Open practices}

The data and analysis script for this study are available on its Open Science Framework page (https://osf.io/sey6x/).

\section{Appendix A. Supplementary data}

Supplementary data to this article can be found online at https:// doi.org/10.1016/j.jesp.2018.02.014.

\section{References}

Aked, J., Marks, N., Cordon, C., \& Thompson, S. (2008). Five ways to wellbeing: The evidence. Retrieved from http://www.neweconomics.org/publications/entry/fiveways-to-well-being-the-evidence.

Aked, J., \& Thompson, S. (2011). Five ways to wellbeing: New applications, new ways of thinking. Retrieved from http://www.neweconomics.org/publications/entry/wellbeing-evidence-for-policy-a-review.

Aknin, L. B., Barrington-Leigh, C. P., Dunn, E. W., Helliwell, J. F., Burns, J., BiswasDiener, R., ... Norton, M. I. (2013). Prosocial spending and well-being: Cross-cultural evidence for a psychological universal. Journal of Personality and Social Psychology, 104(4), 635-652. http://dx.doi.org/10.1037/a0031578.

Aknin, L. B., Broesch, T., Hamlin, J. K., \& Van de Vondervoort, J. W. (2015). Prosocial behavior leads to happiness in a small-scale rural society. Journal of Experimental Psychology: General, 144(4), 788-795. http://dx.doi.org/10.1037/xge0000082.

Aknin, L. B., Dunn, E. W., Sandstrom, G. M., \& Norton, M. I. (2013). Does social connection turn good deeds into good feelings?: On the value of putting the 'social' in prosocial spending. International Journal of Happiness and Development, 1(2), 155-171. http://dx.doi.org/10.1504/ijhd.2013.055643.

Aknin, L. B., Fleerackers, A. L., \& Hamlin, J. K. (2014). Can third-party observers detect the emotional rewards of generous spending? Journal of Positive Psychology, 9(3), 198-203. http://dx.doi.org/10.1080/17439760.2014.888578.

Aknin, L. B., Hamlin, J. K., \& Dunn, E. W. (2012). Giving leads to happiness in young children. PLOS ONE, 7(6), http://dx.doi.org/10.1371/journal.pone.0039211.

Alden, L. E., \& Trew, J. L. (2013). If it makes you happy: Engaging in kind acts increases positive affect in socially anxious individuals. Emotion, 13(1), 64-75. http://dx.doi. org/10.1037/a0027761.

Alvard, M. (2001). Mutualistic hunting. In C. Stanford, \& H. Bunn (Eds.). Meat-eating and human evolution (pp. 261-278). New York: Oxford University Press.

Amici, F., Aureli, F., Mundry, R., Amaro, A., Barroso, A., Ferretti, J., \& Call, J. (2014). Calculated reciprocity? A comparative test with six primate species. Primates, 55(3), 447-457. http://dx.doi.org/10.1007/s10329-014-0424-4.

Anik, L., Aknin, L. B., Norton, M. I., \& Dunn, E. W. (2009). Feeling good about giving: The benefits (and costs) of self-interested charitable behavior - HBS working knowledge Harvard Business School.

Anik, L., Aknin, L. B., Norton, M. I., Dunn, E. W., \& Quoidbach, J. (2013). Prosocial bonuses increase employee satisfaction and team performance. PloS One, 8(9), e75509.

Arnocky, S., Piché, T., Albert, G., Ouellette, D., \& Barclay, P. (2016). Altruism predicts mating success in humans. British Journal of Psychology. http://dx.doi.org/10.1111/ bjop. 12208.

Axelrod, R. (1984). The evolution of cooperation. New York: Basic Books.

Balliet, D., Li, N. P., Macfarlan, S. J., \& Van Vugt, M. (2011). Sex differences in cooperation: A meta-analytic review of social dilemmas. Psychological Bulletin, 137(6), 881-909.

Balliet, D., Wu, J., \& De Dreu, C. K. W. (2014). Ingroup favoritism in cooperation: A metaanalysis. Psychological Bulletin, 140(6), 1556-1581. http://dx.doi.org/10.1037/ a0037737.

Barclay, P. (2011). The evolution of charitable behaviour and the power of reputation. In S. C. Roberts (Ed.). Applied evolutionary psychology. Oxford: Oxford University Press.

Bissonnette, A., Perry, S., Barrett, L., Mitani, J. C., Flinn, M., Gavrilets, S., \& de Waal, F. B. M. (2015). Coalitions in theory and reality: A review of pertinent variables and processes. Behaviour, 152(1), 1-56. http://dx.doi.org/10.1163/1568539X-00003241.

Boinski, S., \& Garber, P. A. (Eds.). (2000). On the move: How and why animals travel in groups. Chicago University Press.

Bolier, L., Haverman, M., Westerhof, G. J., Riper, H., Smit, F., \& Bohlmeijer, E. (2013). Positive psychology interventions: A meta-analysis of randomized controlled studies. BMC Public Health, 13(1), 1-20. http://dx.doi.org/10.1186/1471-2458-13-119.

Boos, M., Kolbe, M., Kappeler, P. M., \& Ellwart, T. (Eds.). (2011). Coordination in human and primate groups. Springer.

Boyd, R., Richerson, P. J., \& Henrich, J. (2011). The cultural niche: Why social learning is essential for human adaptation. PNAS, 108, 10918-10925. http://dx.doi.org/10. 1073/pnas.1100290108.

Buchanan, K. E., \& Bardi, A. (2010). Acts of kindness and acts of novelty affect life satisfaction. Journal of Social Psychology, 150(3), 235-237.

Buss, D. M. (2000). The evolution of happiness. American Psychologist, 55(1), 15-23.

Chancellor, J., Margolis, S., Jacobs Bao, K., \& Lyubomirsky, S. (2017). Everyday prosociality in the workplace: The reinforcing benefits of giving, getting, and glimpsing. Emotion. http://dx.doi.org/10.1037/emo0000321 Advance online publication.

Clutton-Brock, T. H. (2009). Cooperation between non-kin in animal societies. Nature, 462, 51-57.

Cosmides, L., \& Tooby, J. (2005). Neurocognitive adaptations designed for social exchange. In D. M. Buss (Ed.). The handbook of evolutionary psychology (pp. 584-627). NY: Wiley.

Coyne, J. C. (2014a). Failing grade for highly cited meta-analysis of positive psychology interventions. Retrieved from http://blogs.plos.org/mindthebrain/2014/11/18/ failing-grade-highly-cited-meta-analysis-positive-psychology-interventions/.

Coyne, J. C. (2014b). Positive psychology interventions for depressive symptoms. Retrieved from http://blogs.plos.org/mindthebrain/2014/10/28/positivepsychology-interventions-depressive-symptoms/.

Curry, O. S. (2016). Morality as cooperation: A problem-centred approach. In T. K. Shackelford, \& R. D. Hansen (Eds.). The evolution of morality (pp. 27-51). Springer International Publishing.

Delton, A. W., Krasnow, M. M., Cosmides, L., \& Tooby, J. (2011). Evolution of direct reciprocity under uncertainty can explain human generosity in one-shot encounters. Proceedings of the National Academy of Sciences of the United States of America, 108(32), 13335-13340. http://dx.doi.org/10.1073/pnas.1102131108.

Diener, E., Emmons, R. A., Larsen, R. J., \& Griffin, S. (1985). The satisfaction with life scale. Journal of Personality Assessment, 49(1), 71-75. http://dx.doi.org/10.1207/ s15327752jpa4901_13.

Dolan, P., \& Metcalfe, R. (2012). Measuring subjective wellbeing: Recommendations on measures for use by national governments. Journal of Social Policy, 41, 409-427. http://dx.doi.org/10.1017/S0047279411000833.

Donnelly, Grant, E., Lamberton, C., Walker Reczek, R., \& Norton, M. I. (2017). Social recycling transforms unwanted goods into happiness. Journal of the Association for Consumer Research, 2(1), 48-63.

Dunn, E. W., Aknin, L. B., \& Norton, M. I. (2008). Spending money on others promotes happiness. Science, 319(5870), 1687-1688. http://dx.doi.org/10.1126/science. 1150952.

Faul, F., Erdfelder, E., Lang, A.-G., \& Buchner, A. (2007). G*Power 3: A flexible statistical power analysis program for the social, behavioral, and biomedical sciences. Behavior Research Methods, 39(2), 175-191. http://dx.doi.org/10.3758/bf03193146.

Field, A. P., \& Gillett, R. (2010). How to do a meta-analysis. British Journal of Mathematical and Statistical Psychology, 63(3), 665-694. http://dx.doi.org/10.1348/ 000711010 X502733.

Gardner, A., \& West, S. A. (2014). Special issue: Inclusive fitness; 50 years on. Philosophical Transactions of the Royal Society, B: Biological Sciences, 369.

Geary, D. C., \& Flinn, M. V. (2001). Evolution of human parental behavior and the human family. Parenting-Science and Practice, 1(1-2), 5-61. http://dx.doi.org/10.1207/ S15327922par0112_2 (Pii 785828753).

Geenen, N. Y. R., Hohelüchter, M., Langholf, V., \& Walther, E. (2014). The beneficial effects of prosocial spending on happiness: Work hard, make money, and spend it on others? The Journal of Positive Psychology, 9(3), 204-208. http://dx.doi.org/10.1080/ 17439760.2014 .891154$.

Gintis, H., Smith, E. A., \& Bowles, S. (2001). Costly signaling and cooperation. Journal of Theoretical Biology, 213, 103-119. http://dx.doi.org/10.1006/jtbi.2001.2406.

Hamilton, W. D. (1964). The genetical evolution of social behaviour. Journal of Theoretical Biology, 7(1-16), 17-52. http://dx.doi.org/10.1016/0022-5193(64)90039-6.

Hammerstein, P. (Ed.). (2003). Genetic and cultural evolution of cooperation. Cambridge, Mass: MIT Press.

Hanniball, K. B., \& Aknin, L. B. (2016). Does helping others foster happiness in newcomer populations? (unpublished data).

de Waal, F. B. M. (1992). In A. Harcourt (Ed.). Coalitions and alliances in humans and other animals. Oxford: Oxford University Press.

Hardy, C. L., \& Van Vugt, M. (2006). Nice guys finish first: The competitive altruism hypothesis. Personality and Social Psychology Bulletin, 32(10), 1402-1413. http://dx. doi.org/10.1177/0146167206291006.

Hardy, C. W., \& Briffa, M. (Eds.). (2013). Animal contests. Cambridge: Cambridge University Press.

Hawkes, K. (1991). Showing off: Tests of another hypothesis about men's foraging goals. Ethology and Sociobiology, 12(1), 29-54.

Hawkes, K., O'Connell, J. F., \& Blurton Jones, N. G. (2001). Hadza meat sharing. Evolution and Human Behavior, 22(2), 113-142.

Helliwell, J., Layard, R., \& Sachs, J. (2016). World happiness report 2016 update. Retrieved from New York http://worldhappiness.report.

Henrich, J., Heine, S. J., \& Norenzayan, A. (2010). Beyond WEIRD: Towards a broadbased behavioral science. Behavioral and Brain Sciences, 33(2-3), 111-135. http://dx doi.org/10.1017/S0140525x10000725.

Hill, S. E., DelPriore, D. J., \& Major, B. (2013). An evolutionary psychological perspective on happiness. In I. Boniwell, S. A. David, \& A. C. Ayers (Eds.). Oxford handbook of happiness.

Huppert, F. A. (2009). Psychological well-being: Evidence regarding its causes and consequencest. Applied Psychology. Health and Well-Being, 1(2), 137-164. http://dx.doi. org/10.1111/j.1758-0854.2009.01008.x.

Jenkinson, C. E., Dickens, A. P., Jones, K., Thompson-Coon, J., Taylor, R. S., Rogers, M., .. 
Richards, S. H. (2013). Is volunteering a public health intervention? A systematic review and meta-analysis of the health and survival of volunteers. BMC Public Health, 13(1), 1-10. http://dx.doi.org/10.1186/1471-2458-13-773.

Kogan, A., Impett, E. A., Oveis, C., Hui, B., Gordon, A. M., \& Keltner, D. (2010). When giving feels good: The intrinsic benefits of sacrifice in romantic relationships for the communally motivated. Psychological Science, 21(12), 1918-1924. http://dx.doi.org/ $10.1177 / 0956797610388815$.

Konrath, S., \& Brown, S. (2013). The effects of giving on givers. In M. L. Newman, \& N. A. Roberts (Eds.). Health and social relationships: The good, the bad, and the complicated (pp. 39-64). Washington: American Psychological Association.

Konrath, S., Fuhrel-Forbis, A., Lou, A., \& Brown, S. (2012). Motives for volunteering are associated with mortality risk in older adults. Health Psychology, 31(1), 87-96. http:// dx.doi.org/10.1037/a0025226.

Kraft-Todd, G., Yoeli, E., Bhanot, S., \& Rand, D. (2015). Promoting cooperation in the field. Current Opinion in Behavioral Sciences, 3, 96-101. http://dx.doi.org/10.1016/j cobeha.2015.02.006.

Krasnow, M. M., Delton, A. W., Tooby, J., \& Cosmides, L. (2013). Meeting now suggests we will meet again: Implications for debates on the evolution of cooperation. Scientific Reports, 3. http://dx.doi.org/10.1038/srep01747.

Lamers, S. M. A., Westerhof, G. J., Bohlmeijer, E. T., ten Klooster, P. M., \& Keyes, C. L. M. (2011). Evaluating the psychometric properties of the mental health ContinuumShort Form (MHC-SF). Journal of Clinical Psychology, 67(1), 99-110. http://dx.doi. org $/ 10.1002 /$ jclp. 20741 .

Layous, K., Kurtz, J., Margolis, S., Chancellor, J., \& Lyubomirsky, S. (2017). Make someone happy and you will be happy too: An other-oriented path to well-being. Manuscript submitted for publication.

Layous, K., Lee, H., Choi, I., \& Lyubomirsky, S. (2013). Culture matters when designing a successful happiness-increasing activity: A comparison of the United States and South Korea. Journal of Cross-Cultural Psychology, 44(8), 1294-1303. http://dx.doi.org/10. 1177/0022022113487591.

Layous, K., Nelson, S. K., Oberle, E., Schonert-Reichl, K. A., \& Lyubomirsky, S. (2012). Kindness counts: Prompting prosocial behavior in preadolescents boosts peer acceptance and well-being. PLoS ONE, 7(12), http://dx.doi.org/10.1371/journal.pone. 0051380.

Lehmann, L., \& Keller, L. (2006). The evolution of cooperation and altruism - A general framework and a classification of models. Journal of Evolutionary Biology, 19(5), 1365-1376. http://dx.doi.org/10.1111/j.1420-9101.2006.01119.x.

Lenhard, W., \& Lenhard, A. (2016). Calculation of effect sizes. Psychometrica. Retrieved from https://www.psychometrica.de/effect_size.html.

Lieberman, D., Tooby, J., \& Cosmides, L. (2007). The architecture of human kin detection. Nature, 445(7129), 727-731. http://dx.doi.org/10.1038/Nature05510.

Lyubomirsky, S., \& Lepper, H. S. (1999). A measure of subjective happiness: Preliminary reliability and construct validation. Social Indicators Research, 46(2), 137-155. http:// dx.doi.org/10.1023/A:1006824100041.

Lyubomirsky, S., Sheldon, K. M., \& Schkade, D. (2005). Pursuing happiness: The architecture of sustainable change. Review of General Psychology, 9(2), 111-131. http://dx. doi.org/10.1037/1089-2680.9.2.111.

Martela, F., \& Ryan, R. M. (2016). Prosocial behavior increases well-being and vitality even without contact with the beneficiary: Causal and behavioral evidence. Motivation and Emotion, 40(3), 351-357. http://dx.doi.org/10.1007/s11031-0169552-z.

Mateo, J. M. (2015). Perspectives: Hamilton's legacy: Mechanisms of kin recognition in humans. Ethology: formerly Zeitschrift fur Tierpsychologie, 121(5), 419-427. http://dx. doi.org/10.1111/eth.12358.

Maynard Smith, J., \& Price, G. R. (1973). The logic of animal conflict. Nature, 246, 15-18.

Mazur, A. (2005). Biosociology of dominance and deference. Lanham, Maryland: Rowan Littlefield.

McCullough, M. E., Kurzban, R., \& Tabak, B. A. (2013). Cognitive systems for revenge and forgiveness. Behavioral and Brain Sciences, 36(01), 1-15. http://dx.doi.org/10.1017/ S0140525X11002160.

Miller, G. F. (2000). The mating mind. London: William Heinemann.

Mongrain, M., Chin, J. M., \& Shapira, L. B. (2011). Practicing compassion increases happiness and self-esteem. Journal of Happiness Studies, 12(6), 963-981. http://dx. doi.org/10.1007/s10902-010-9239-1.

Nelson, S. K., Della Porta, M. D., Bao, K. J., Lee, H. C., Choi, I., \& Lyubomirsky, S. (2015). 'It's up to you': Experimentally manipulated autonomy support for prosocial behavior improves well-being in two cultures over six weeks. The Journal of Positive Psychology, 10(5), 463-476. http://dx.doi.org/10.1080/17439760.2014.983959.

Nelson, S. K., Layous, K., Cole, S. W., \& Lyubomirsky, S. (2016). Do unto others or treat yourself? The effects of prosocial and self-focused behavior on psychological flourishing. Emotion. http://dx.doi.org/10.1037/emo0000178.supp (Supplemental).

Nunn, C. L., \& Lewis, R. J. (2001). Cooperation and collective action in animal behaviour. Economics in nature: Social Dilemmas, mate choice and biological markets (pp. 42-66). Cambridge: CUP.

O'Connell, B. H., O'Shea, D., \& Gallagher, S. (2016). Enhancing social relationships through positive psychology activities: A randomised controlled trial. The Journal of Positive Psychology, 11(2), 149-162. http://dx.doi.org/10.1080/17439760.2015. 1037860 .

OECD (2013). OECD guidelines on measuring subjective well-being. OECD Publishing.

Ouweneel, E., Le Blanc, P. M., \& Schaufeli, W. B. (2014). On being grateful and kind: Results of two randomized controlled trials on study-related emotions and academic engagement. The Journal of Psychology, 148(1), 37-60. http://dx.doi.org/10.1080/ 00223980.2012 .742854 .

Pascal, B. (1669). Pensées.
Petersen, M. B. (2012). Social welfare as small-scale help: Evolutionary psychology and the deservingness heuristic. American Journal of Political Science, 56(1), 1-16. http:// dx.doi.org/10.1111/j.1540-5907.2011.00545.x.

Pinker, S. (2010). The cognitive niche: Coevolution of intelligence, sociality, and language. Proceedings of the National Academy of Sciences of the United States of America, 107, 8993-8999. http://dx.doi.org/10.1073/pnas.0914630107.

Platek, S. M., Burch, R. L., Panyavin, I. S., Wasserman, B. H., \& Gallup, G. G., Jr. (2002). Reactions to children's faces: Resemblance affects males more than females. Evolution and Human Behavior, 23, 159-166.

Qualter, P., Vanhalst, J., Harris, R., Van Roekel, E., Lodder, G., Bangee, M., ... Verhagen, M. (2015). Loneliness across the life span. Perspectives on Psychological Science, 10(2), 250-264. http://dx.doi.org/10.1177/1745691615568999.

R Core Team (2017). R: A language and environment for statistical computing. Vienna, Austria: R Foundation for Statistical Computing. Retrieved from https://www.R project.org/.

Raihani, N. J., \& Bshary, R. (2015). Why humans might help strangers. Frontiers in Behavioral Neuroscience, 9(39), http://dx.doi.org/10.3389/fnbeh.2015.00039.

Raihani, N. J., \& Smith, S. (2015). Competitive helping in online giving. Current Biology, 25(9), 1183-1186. http://dx.doi.org/10.1016/j.cub.2015.02.042.

Riechert, S. E. (1998). Game theory and animal contests. In L. A. Dugatkin, \& H. K. Reeve (Eds.). Game theory and animal behavior (pp. 64-93). Oxford: Oxford University Press.

Roberts, G. (2008). Evolution of direct and indirect reciprocity. Proceedings of the Royal Society B: Biological Sciences, 275(1631), 173.

Rosenthal, R. (1979). The file drawer problem and tolerance for null results. Psychological Bulletin, 86(3), 638-641.

Royle, N. J., Smiseth, P. T., \& Kölliker, M. (Eds.). (2012). The evolution of parental care. OUP.

Ryan, R. M., \& Deci, E. L. (2001). On happiness and human potentials: A review of research on hedonic and eudaimonic well-being. Annual Review of Psychology, 52, 141-166. http://dx.doi.org/10.1146/annurev.psych.52.1.141.

Sachs, J. L., Mueller, U. G., Wilcox, T. P., \& Bull, J. J. (2004). The evolution of cooperation. The Quarterly Review of Biology, 79(2), 135-160. http://dx.doi.org/10. $1086 / 383541$

Schulkin, J. (2011). Adaptation and well-being: social allostasis. Cambridge University Press.

Seligman, M. E. P., Steen, T. A., Park, N., \& Peterson, C. (2005). Positive psychology progress - Empirical validation of interventions. American Psychologist, 60(5), 410-421. http://dx.doi.org/10.1037/0003-066x.60.5.410.

Shultz, S., Opie, C., \& Atkinson, Q. D. (2011). Stepwise evolution of stable sociality in primates. Nature, 479(7372), 219-222. http://www.nature.com/nature/journal/ v479/n7372/abs/nature10601.html\#supplementary-information.

Sin, N. L., \& Lyubomirsky, S. (2009). Enhancing well-being and alleviating depressive symptoms with positive psychology interventions: A practice-friendly meta-analysis. Journal of Clinical Psychology, 65(5), 467-487. http://dx.doi.org/10.1002/jclp. 20593.

Smith, E. A., \& Bleige Bird, R. L. (2000). Turtle hunting and tombstone opening: Public generosity as costly signaling. Evolution and Human Behavior, 21, 245-261.

Sznycer, D., Al-Shawaf, L., Bereby-Meyer, Y., Curry, O. S., De Smet, D., Ermer, E., ... Tooby, J. (2017). Cross-cultural regularities in the cognitive architecture of pride. Proceedings of the National Academy of Sciences, 114(8), 1874. http://dx.doi.org/10. 1073/pnas.1614389114.

Tanimoto, J. (2015). Network reciprocity. In J. Tanimoto (Ed.). Fundamentals of evolutionary game theory and its applications (pp. 69-141). Tokyo: Springer Japan.

Trew, J. L., \& Alden, L. E. (2015). Kindness reduces avoidance goals in socially anxious individuals. Motivation and Emotion, 39(6), 892-907. http://dx.doi.org/10.1007/ s11031-015-9499-5.

Trivers, R. L. (1971). The evolution of reciprocal altruism. Quarterly Review of Biology, 46(1), 35-57. http://dx.doi.org/10.1086/406755.

Van den Noortgate, W., López-López, J. A., Marín-Martínez, F., \& Sánchez-Meca, J. (2015). Meta-analysis of multiple outcomes: A multilevel approach. Behavior Research Methods, 47(4), 1274-1294. http://dx.doi.org/10.3758/s13428-014-0527-2.

Van Lissa, C. J. (2017). MetaForest: Exploring heterogeneity in meta-analysis using random forests. Open Science Framework. http://dx.doi.org/10.17605/OSF.IO/ KHJGB.

Viechtbauer, W. (2010). Conducting meta-analyses in R with the metafor package. Journal of Statistical Software, 36(3), 1-48.

Watson, D., Clark, L. A., \& Tellegen, A. (1988). Development and validation of brief measures of positive and negative affect - the Panas scales. Journal of Personality and Social Psychology, 54(6), 1063-1070. http://dx.doi.org/10.1037/0022-3514.54.6. 1063.

Weiss, L. A., Westerhof, G. J., \& Bohlmeijer, E. T. (2016). Can we increase psychological well-being? The effects of interventions on psychological well-being: A meta-analysis of randomized controlled trials. PLoS One, 11(6), e0158092. http://dx.doi.org/10. 1371/journal.pone.0158092.

Whillans, A. V., Dunn, E. W., Sandstrom, G. M., Dickerson, S. S., \& Madden, K. M. (2016) Is spending money on others good for your heart? Health Psychology, 35(6), 574-583. http://dx.doi.org/10.1037/hea0000332.

Whitehouse, H., \& Lanman, J. A. (2014). The ties that bind us ritual, fusion, and identification. Current Anthropology, 55(6), 674-695. http://dx.doi.org/10.1086/678698.

Wrangham, R. (1999). Evolution of coalitionary killing. Yearbook of Physical Anthropology, 42, 1-30.

Zahavi, A., \& Zahavi, A. (1997). The handicap principle: A missing piece of Darwin's puzzle Oxford: Oxford Univerity Press. 